\title{
Uncertainty in aerosol hygroscopicity resulting from semi-volatile organic compounds
}

\author{
Olivia Goulden, Matthew Crooks, and Paul Connolly \\ The School of Earth, Atmospheric and Environmental Science, The University of Manchester, Oxford Road, \\ Manchester, M13 9PL, UK
}

Correspondence: Matthew Crooks (matthew.crooks@manchester.ac.uk)

Received: 31 March 2017 - Discussion started: 18 April 2017

Revised: 26 September 2017 - Accepted: 26 September 2017 - Published: 10 January 2018

\begin{abstract}
We present a novel method of exploring the effect of uncertainties in aerosol properties on cloud droplet number using existing cloud droplet activation parameterisations. Aerosol properties of a single involatile particle mode are randomly sampled within an uncertainty range and resulting maximum supersaturations and critical diameters calculated using the cloud droplet activation scheme. Hygroscopicity parameters are subsequently derived and the values of the mean and uncertainty are found to be comparable to experimental observations. A recently proposed cloud droplet activation scheme that includes the effects of co-condensation of semi-volatile organic compounds (SVOCs) onto a single lognormal mode of involatile particles is also considered. In addition to the uncertainties associated with the involatile particles, concentrations, volatility distributions and chemical composition of the SVOCs are randomly sampled and hygroscopicity parameters are derived using the cloud droplet activation scheme. The inclusion of SVOCs is found to have a significant effect on the hygroscopicity and contributes a large uncertainty. For non-volatile particles that are effective cloud condensation nuclei, the co-condensation of SVOCs reduces their actual hygroscopicity by approximately $25 \%$. A new concept of an effective hygroscopicity parameter is introduced that can computationally efficiently simulate the effect of SVOCs on cloud droplet number concentration without direct modelling of the organic compounds. These effective hygroscopicities can be as much as a factor of 2 higher than those of the non-volatile particles onto which the volatile organic compounds condense.
\end{abstract}

\section{Introduction}

The Earth's weather and climate are both strongly influenced by clouds (Morgan et al., 2010; Ohring and Clapp, 1980). Cloud droplet number concentration and size can have a significant effect on cloud albedo by changing the amount of reflected shortwave radiation and absorbed longwave radiation (Twomey, 1977; McCormick and Ludwig, 1967). In addition, the abundance of cloud droplets and their properties can influence precipitation rate and subsequently cloud lifetime (Stevens and Feingold, 2009; Albrecht, 1989), which itself has a strong interdependency with cloud albedo (Twomey, 1974, 1977). The net global mean radiative forcing is estimated to be reduced by about $0.45 \mathrm{~W} \mathrm{~m}^{-2}$ as a result of aerosol-cloud interactions (Forster et al., 2007). This figure, however, is subject to a large degree of uncertainty.

In general, there is a positive correlation between aerosol number concentration and cloud droplet number concentration (Twomey, 1959), however, the details are much more complex. According to Köhler theory (Köhler, 1936), the presence of sufficiently large aerosol particles can impede the growth, and subsequent activation, of smaller particles in a polydisperse aerosol by reducing the water available to activate the remaining cloud condensation nuclei (CCN) (Ghan et al., 1998). Size and composition are significant in establishing how effectively individual aerosol particles will act as CCN (Pruppacher and Klett, 1977). In addition, the effects of other atmospheric constituents, such as surfactants, can be equally as important in determining cloud droplet number as the number concentration of aerosol particles (Lance et al., 2004; Nenes et al., 2002).

A dominant factor influencing aerosol composition is the co-condensation of semi-volatile organic com- 
pounds (SVOCs) onto CCN (Topping and McFiggans, 2012). Köhler theory is limited to non-volatile compounds, so it does not consider the effects of compounds of ranging volatility in the atmosphere. It has been shown that SVOCs increase the tendency for activation of $\mathrm{CCN}$, which consequently affects radiative properties of clouds and hence the necessity to quantify their influence (Topping et al., 2013).

Depending on geographical location, between 5 and $90 \%$ of total aerosol mass can be composed of organic material (Andreae and Crutzen, 1997; Zhang et. al., 2007; Gray et al., 1986). A portion of this will originate from primary sources, but a significant and uncertain amount will be produced by secondary processes, namely nucleation of new particles and condensation of SVOCs onto existing particles. The former process increases the number concentration of aerosol particles while the latter increases the size, and consequently soluble mass, of existing aerosol particles. The enlarged size and altered chemical composition of the particles has a dominant effect on cloud droplet number (Dusek et al., 2006; Topping et al., 2013), and so uncertainties in the amount and composition of secondary organic aerosol mass translate into large uncertainties in cloud properties.

Multiple parameterisations of cloud droplet activation have been developed (Fountoukis and Nenes, 2005; AbdulRazzak et al., 1998; Abdul-Razzak and Ghan, 2000; Shipway and Abel, 2010; Ming et al., 2005) and have been effective at estimating $\mathrm{CCN}$ concentrations at a range of atmospherically applicable conditions (Ghan et al., 2011; Simpson et al., 2014) whilst being more computationally efficient than a detailed cloud parcel model. Although the work of Fountoukis and Nenes (2005) and Abdul-Razzak et al. (1998) has shown to be representative of physical processes (Ghan et al., 2011), they lack the consideration of co-condensation of organic vapours.

Connolly et al. (2014) extended the parameterisations of Fountoukis and Nenes (2005) and Abdul-Razzak et al. (1998) to incorporate the effects of co-condensation of SVOCs in the presence of a single non-volatile aerosol mode with lognormally distributed particle sizes. This is achieved by first assuming the SVOCs are in equilibrium between a vapour and condensed phase at the initial temperature, pressure and relative humidity, calculated using a molar-based equilibrium absorptive partitioning theory (Barley et al., 2009). The additional mass from the condensed phase of the organics is added to the non-volatile constituent and the particle size distribution altered so that the number concentration and geometric standard deviation are the same as the non-volatile mode but the median diameter is increased to conserve mass. Equilibrium absorptive partitioning theory at cloud base $(99.999 \% \mathrm{RH})$ is then used to calculate additional aerosol mass from the organics, but both the median diameter and geometric standard deviation are changed to simulate the condensed phase of SVOCs after undergoing dynamic condensation during cloud activation. This is carried out whilst maintaining arithmetic standard deviation and conserving mass. The aerosol size distribution and material properties at cloud base are then input into the existing cloud droplet activation schemes of Fountoukis and Nenes (2005) and Abdul-Razzak et al. (1998). The Fountoukis and Nenes (2005) parameterisation was found to most successfully replicate the results from a detailed parcel model with binned microphysics and is, consequently, the only parameterisation considered in this paper. This parameterisation was later extended to include multiple non-volatile aerosol modes (Crooks et al., 2017).

Petters and Kreidenweis (2007) present the hygroscopicity, $\kappa$, as a method of characterising $\mathrm{CCN}$ activity through relating dry diameter and supersaturation into a single parameter. Typically, for atmospheric aerosol the hygroscopicity lies in the range $0.1<\kappa<0.9$ with insoluble particles having a $\kappa$ of approximately zero and $\kappa>1$, indicating particles that are highly effective as $\mathrm{CCN}$, such as sodium chloride. The hygroscopicity parameter is capable of quantifying water uptake characteristics for internally mixed particles, and aids in interpreting $\mathrm{CCN}$ particles where the composition is not fully known by fitting to experimental data. Alternatively, when composition is known, a volume-averaged mixing rule can be used to determine $\kappa$.

In the case of involatile particles, the hygroscopicity depends solely on chemical composition and is independent of particle size. In environments that contain SVOCs, the hygroscopicity becomes more ambiguous. Due to the condensed mass of SVOCs depending on relative humidity, aerosol particles have chemical compositions and sizes that vary with the RH. Consequently, the properties of aerosol particles, including the hygroscopicity, change drastically as they rise in the atmosphere from subsaturated air into cloud.

In field measurements, atmospheric aerosol is passed through instruments under subsaturated conditions in order to measure the size distribution and composition (Taylor et al., 2016), while the number of $\mathrm{CCN}$ is calculated under supersaturated conditions. Including the production, condensation, evaporation, reaction and oxidation of SVOCs directly in large-scale models is very computationally expensive and is rarely carried out, especially for more than one compound. For the purposes of aerosol transport, it is common to apply equilibrium absorptive partitioning theory to calculate the particle phase of volatile compounds (Topping and McFiggans, 2012). Comprehensively including the effect of SVOCs on cloud droplet activation in large-scale models is yet to be carried out (Ervens, 2015). Although a number of studies have attempted to parameterise the relation between secondary organic aerosol and cloud liquid water content (Myriokefalitakis et al., 2011; Lin et al., 2014), an effective cloud droplet radius has to be assumed in order to incorporate them into large-scale models.

In Sect. 2.1, we describe the set up of the Monte Carlo simulations in the simpler involatile aerosol case before making comparisons with analogous experimental results from the literature in Sect. 2.2. A discussion of the modifications and 
extensions to the Monte Carlo scheme to include SVOCs is presented in Sect. 3.2. In Sect. 3.3, a method of including cocondensation of SVOCs in large-scale models is proposed.

\section{Hygroscopicity of involatile aerosol}

\subsection{Methodology}

There are many sources of uncertainties discussed in this paper and, in order to study their effect on cloud droplet formulation, we encapsulate the uncertainty into a single parameter called the hygroscopicity. The hygroscopicity parameter, $\kappa$, introduced by Petters and Kreidenweis (2007), which is defined as

$\kappa=\frac{4 A^{3}}{27 D_{\mathrm{d}}^{3} \ln ^{2} S_{c}}$.

Here $D_{\mathrm{d}}$ is the diameter of the dry particle that activates at a percentage supersaturation of $s_{c}=\left(S_{c}-1\right) \times 100$, where $S_{c}$ is the saturation ratio. The parameter $A$ is defined as

$A=\frac{4 \tau M_{\mathrm{w}}}{R T \rho_{\mathrm{w}}}$,

where $\tau$ is the surface tension of water, $M_{\mathrm{w}}$ and $\rho_{\mathrm{w}}$ are the molecular weight and density of water, and $R$ and $T$ are the universal gas constant and temperature, respectively.

Both the critical diameter and supersaturation are dependent on the chemical composition of the aerosol particles with less hygroscopic particles requiring a larger supersaturation to activate, which also corresponds to a larger critical diameter. Typically, the critical diameter and supersaturation pairs are obtained from experiments (Svenningsson et al., 2006), (Dinar et al., 2006; Petters et al., 2006) but this is a costly and time-consuming process. In order to calculate the sensitivity of $\kappa$ to each parameter, a large number of experiments are required. In this paper, a cloud activation parameterisation (Fountoukis and Nenes, 2005) is used to calculate the critical diameter and supersaturation as a function of the aerosol properties. For each set of parameter values, the parameterisation can calculate the critical supersaturation and number of $\mathrm{CCN}$ in under a second. Consequently, this approach offers a practical method to perform a large number of simulations to fully explore the dependence of $\kappa$ on the different model parameters.

In this section we demonstrate how the parameterisations can be used to calculate the uncertainty in $\kappa$ for common non-volatile compounds before extending the method to include SVOCs in Sect. 3.1. This section demonstrates that the uncertainty in the size distribution that we simulate produces similar uncertainty in $\kappa$ that are observed in experiments. It also offers a comparison of the uncertainty in $\kappa$ that result from the inclusion of the SVOCs in Sects. 3.1.
Particle sizes are assumed to follow a lognormal size distribution of the form

$$
\frac{\mathrm{d} N}{\mathrm{~d} \ln D}=\frac{N}{\sqrt{2 \pi} \ln \sigma} \exp \left[-\left(\frac{\ln \left(D / D_{\mathrm{m}}\right)}{\sqrt{2} \ln \sigma}\right)^{2}\right],
$$

where $N, D_{\mathrm{m}}$ and $\ln \sigma$ are the aerosol number concentration, median diameter and geometric standard deviation, respectively. The cloud droplet activation scheme calculates a maximum supersaturation, $s_{\max }$, and a number of $\mathrm{CCN}$, which we denote $N_{\mathrm{CCN}}$. We define the critical diameter, $D_{\mathrm{d}}$, as the smallest diameter of particle that activates, assuming all larger particles also activate. As such, the critical diameter can be obtained by integrating the size distribution (Eq. 2), with respect to $D$ from $D_{\mathrm{d}}$ up to infinity and equating to the number of $\mathrm{CCN}$ calculated by the parameterisation. Therefore, $D_{\mathrm{d}}$ satisfies

$\frac{1}{2} N \operatorname{erfc}\left(-\frac{\ln \left(D_{\mathrm{d}} / D_{\mathrm{m}}\right)}{\ln \sigma \sqrt{2}}\right)=N_{\mathrm{CCN}}$,

where erfc is the complementary error function.

In order to encapsulate the uncertainty in the measured size distribution in $\kappa$, we first ran a Monte Carlo simulation that solves the parameterisation with each size distribution parameter sampled from normal distributions with specified mean and uncertainty. The range of aerosol size distributions that this corresponds to is represented by the grey shaded region in the lower plot of Fig. 1. In this section we ignore the volatility distribution of SVOCs and the mean dry aerosol size at $50 \% \mathrm{RH}$ is the mean value of the involatile aerosol. After running the parameterisation, a range of $s_{\max }$ and $N_{\mathrm{CCN}}$ are obtained; examples of the resulting probability distributions are shown by the bar charts with blue bars in Fig. 1. The mean and standard deviation of $s_{\max }$ and $N_{\mathrm{CCN}}$ are calculated to produce approximate normal probability distributions, shown by the solid black lines. To calculate $\kappa$, a random pair of $s_{\max }$ and $N_{\mathrm{CCN}}$ were selected at random from their probability distributions (solid black lines). The value of $N_{\mathrm{CCN}}$ and the mean value of $D_{\mathrm{m}}$ were used to calculate the critical diameter, $D_{\mathrm{d}}$, through Eq. (3). This, together with $s_{\max }$, was used to calculate $\kappa$ using Eq. (1) by setting $s_{c}=s_{\max }$.

The focus of this paper is on the effect of SVOCs on the hygroscopicity and, consequently, a thorough analysis of the sensitivity of $\kappa$ to the mean values assigned to the number concentration, median diameter and geometric standard deviation of the non-volatile particle size distribution is not performed. Plots showing the effects for a few select choices of mean size distribution parameters are given in the Supplement. The mean values and standard deviations that are used in the main body of this paper are given in Table 1 . The Monte Carlo simulations are run at 10 different logarithmically spaced updraught velocities ranging from 0.01 to $10 \mathrm{~m} \mathrm{~s}^{-1}$. Each updraught velocity produces a different mean value of $S_{\max }$, but the resulting hygroscopicity shows little 


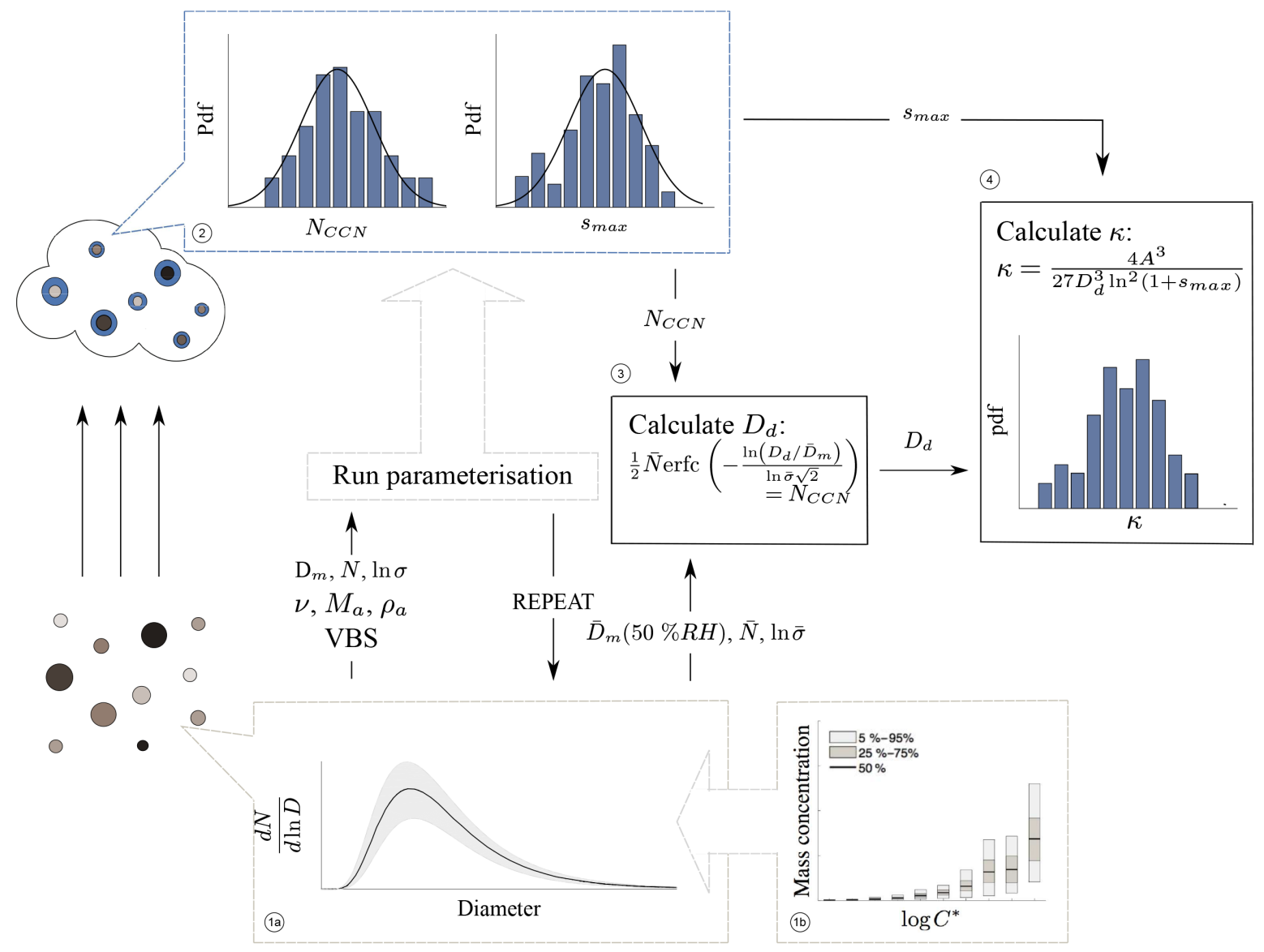

Figure 1. A schematic of the Monte Carlo method to calculate the hygroscopicity, $\kappa$. Mean size distribution and uncertainty range are shown in the plot of step 1a by the solid black line and grey shaded regions, respectively. The volatility basis set (VBS) and uncertainty range used in Sect. 3.1 are shown in the additional plot of $1 \mathrm{~b}$. The blue bar charts in step 2 show the probability distributions of $N_{\mathrm{CCN}}$ and $s_{\text {max }}$ generated from the Monte Carlo simulations that are run using the size distribution parameters and the volatility distributions from step 1 . Randomly chosen van 't Hoff factors $(v)$, molecular weights $\left(M_{\mathrm{a}}\right)$ and densities $\left(\rho_{\mathrm{a}}\right)$ of the aerosol components are also input into the parameterisation. Normal distributions of $N_{\mathrm{CCN}}$ and $s_{\mathrm{max}}$ are fitted to the bar charts and are shown by the overlaid solid black lines. Step 3 combines the mean size distribution of dry aerosol at $50 \% \mathrm{RH}$ with randomly sampled $N_{\mathrm{CCN}}$ to calculate a range of $D_{\mathrm{d}}$. In step 4, each $D_{\mathrm{d}}$ is used together with a randomly sampled $s_{\max }$ to find the range of $\kappa$.

Table 1. Mean and standard deviation of the size distribution parameters of the non-volatile particles.

\begin{tabular}{lrr}
\hline Parameter & Mean & $\begin{array}{r}\text { Standard } \\
\text { deviation }\end{array}$ \\
\hline$N\left(\mathrm{~cm}^{-3}\right)$ & 1000 & 100 \\
$D_{\mathrm{m}}(\mathrm{nm})$ & 100 & 10 \\
$\ln \sigma$ & 0.5 & 0.1 \\
\hline
\end{tabular}

dependence and for this reason the choice of updraught velocity is arbitrary.

To simulate the uncertainty in the solubility and dissociation we randomly sampled the van 't Hoff factors from normal distributions with means, standard deviations and maximum and minimum values stated in Table 2. The maxima
Table 2. Parameters of the normal distributions from which the van 't Hoff factors are sampled; the standard deviations are chosen to be $10 \%$ of the mean. Randomly sampled values that lie outside of the range of the minimum and maximum are ignored.

\begin{tabular}{lrrrr}
\hline Compound & Minimum & Mean & $\begin{array}{r}\text { Maximum } \\
\text { deviation }\end{array}$ & Standard \\
\hline Levoglucosan & 0 & 1 & 2 & 0.1 \\
Ammonium sulfate & 0 & 2.7 & 3 & 0.27 \\
Sodium chloride & 0 & 2 & 2 & 0.2 \\
Sulfuric acid & 0 & 3 & 3 & 0.3 \\
\hline
\end{tabular}

for ammonium sulfate, sodium chloride and sulfuric acid are dictated by ideal behaviour, while the maximum for levoglucosan is chosen to avoid erroneously high values. 


\subsection{Results for involatile aerosol}

Using the methodology described in Sect. 2.1, we produced a range of $\kappa$ for four test compounds: levoglucosan, ammonium sulfate, sodium chloride and sulfuric acid. Although our method is more similar to the $\mathrm{CCN}$-derived $\kappa$, our results are also compared against the values calculated using a growth factor. This is due to the lack of experimental uncertainty for the $\mathrm{CCN}$-derived $\kappa$. Of our four test compounds, only levoglucosan has $\mathrm{CCN}$-derived mean and uncertainty. For comparison, Table 3 shows the mean values and uncertainties from both experimental methods, where available.

Our Monte Carlo simulation was run for 1000 different particle size distributions, each of which were run at 10 different updraughts, evenly distributed in log space from 0.01 to $10 \mathrm{~m} \mathrm{~s}^{-1}$. This produced a range of $N_{\mathrm{CCN}}$ and $s_{\max }$ for each of the four compounds. Using these values, we were able to calculate a range of critical diameters, $D_{\mathrm{d}}$, using the method described in Sect. 2.1. The $D_{\mathrm{d}}$ combined with their corresponding value of $s_{\max }$ resulted in a range of $\kappa$, using Eq. (1). We have chosen to use the 16 th and 84 th quantiles to represent the uncertainty in $\kappa$. This allows for non-symmetric uncertainties but is approximately the same as the standard deviation if the $\kappa$ values are normally distributed.

In Fig. 2, the growth-factor-derived $\kappa$ values from Table 3 are plotted against our calculated hygroscopicity, which will be referred to as $\kappa_{\mathrm{nv}}$. The mean values of each compound are displayed by the dots and the horizontal error bars depict the growth-factor-derived $\kappa_{\text {low }}$ and $\kappa_{\text {up }}$. The vertical error bars show the 16th and 84th quantiles of the range of $\kappa$ values from our method and the grey dashed line shows the $1: 1$ line. The mean $\mathrm{CCN}$-derived $\kappa$ and the mean values from our data are shown by the crosses.

The mean values that our method calculate are in excellent agreement with those given in Table 3 . The growth-factorderived hygroscopicity for sulfuric acid is noticeably lower than $\kappa_{\mathrm{nv}}$ but the CCN-derived hygroscopicity is in much better agreement. The error bars from our Monte Carlo simulations are comparable to those from the growth-factor-derived $\kappa$. Although no uncertainty is available for sulfuric acid, the error bars in $\kappa_{\mathrm{nv}}$ are comparable to those for ammonium sulfate and sodium chloride. In general, our method results in an uncertainty on the order of $20-40 \%$ for all compounds.

\section{Hygroscopicity including the effects of SVOCs}

The volatile nature of SVOCs results in new pathways through which the SVOCs affect $\kappa$ that are not present in the non-volatile particle case. The $\mathrm{CCN}$-based approach to calculating $\kappa$ requires integrating the aerosol size distribution to find the diameter, $D_{\mathrm{d}}$, above which particles activate. The aerosol size distribution, in this case, is measured at subsaturated conditions, typically $\approx 50 \%$ RH (Taylor et al., 2016). The number of particles that activate, however, is controlled

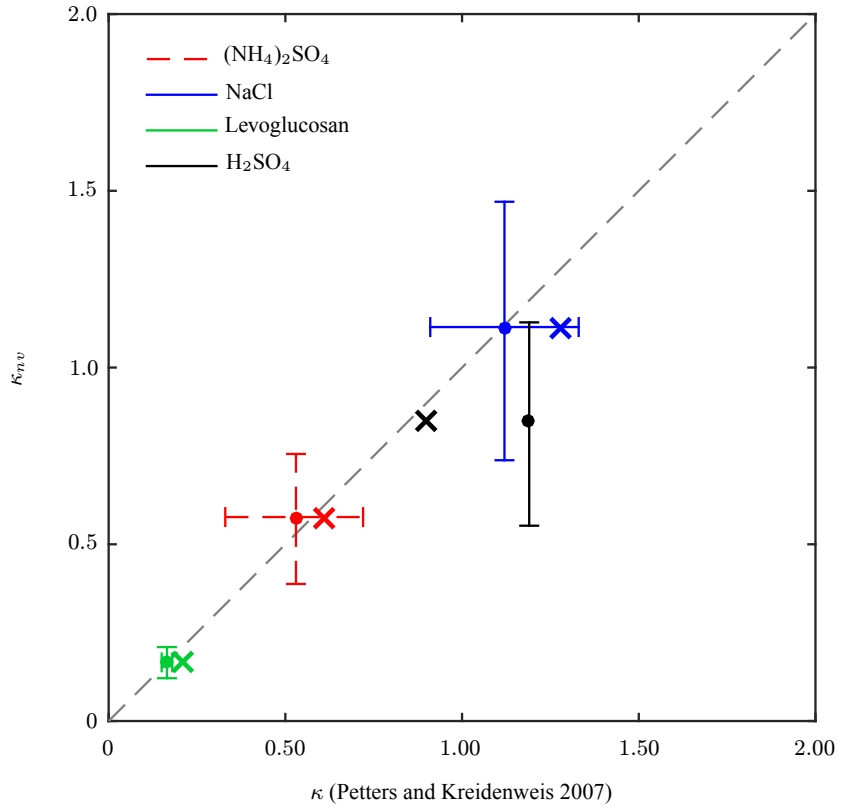

Figure 2. Growth-factor-derived hygroscopicity, $\kappa$, of non-volatile compounds from Petters and Kreidenweis (2007) plotted against the values from our Monte Carlo approach. Mean values from the CCNderived and growth-factor-derived experimental methods are shown by the crosses and dots, respectively, with $y$ coordinates showing the mean from our approach. Horizontal error bars show $\kappa_{\text {low }}$ and $\kappa_{\text {up }}$ from the growth-factor-derived $\kappa$ given in Table 3, and the vertical error bars show the 16th and 84th quantiles of our derived values. Ammonium sulfate is shown in red with dashed error bars, sodium chloride is shown in blue, levoglucosan is shown in green and sulfuric acid is shown in black.

by the chemical composition and size of the aerosol under supersaturated conditions. This is also true of the maximum supersaturation, $s_{\max }$, that is calculated in the parameterisation. For well-mixed internal mixtures, the hygroscopicity of aerosol can be related to the hygroscopicity of each individual compound through the mixing rule of Petters and Kreidenweis (2007),

$\kappa=\sum_{i} \epsilon_{i} \kappa_{i}$

Here, $\kappa_{i}$ is the hygroscopicity of the $i$ th compound and $\epsilon_{i}$ is the volume fraction of the aerosol occupied by that compound. The mixing rule (Eq. 4) can still be used for the case with SVOCs but the volume fractions, $\epsilon_{i}$, and consequently the hygroscopicity, of the aerosol as a whole will vary with time. In particular, the chemical composition and hygroscopicity will be different in cloud to in subsaturated air.

We introduce three single-parameter measures of the hygroscopicity that incorporate the SVOCs in different ways. The first, which we denote by $\kappa_{\mathrm{SVOC}}$, is calculated using a supersaturation and $\mathrm{CCN}$ concentration calculated in cloud and calculate the critical diameter of the dry aerosol using 
Table 3. Growth-factor- and CCN-derived mean and uncertainties in $\kappa$ taken from Petters and Kreidenweis (2007).

\begin{tabular}{lrrrrrrrr}
\hline & \multicolumn{3}{c}{ Growth factor } & & \multicolumn{3}{c}{ CCN } \\
\cline { 2 - 4 } \cline { 7 - 9 } Compound & $\kappa_{\text {low }}$ & $\kappa_{\text {mean }}$ & $\kappa_{\text {up }}$ & & $\kappa_{\text {low }}$ & $\kappa_{\text {mean }}$ & $\kappa_{\text {up }}$ \\
\hline Levoglucosan & 0.15 & 0.165 & 0.18 & & 0.193 & 0.208 & 0.223 \\
Ammonium sulfate & 0.33 & 0.53 & 0.72 & & $\mathrm{n} / \mathrm{a}$ & 0.61 & $\mathrm{n} / \mathrm{a}$ \\
Sodium chloride & 0.91 & 1.12 & 1.33 & & $\mathrm{n} / \mathrm{a}$ & 1.28 & $\mathrm{n} / \mathrm{a}$ \\
Sulfuric acid & $\mathrm{n} / \mathrm{a}$ & 1.19 & $\mathrm{n} / \mathrm{a}$ & & $\mathrm{n} / \mathrm{a}$ & 0.9 & $\mathrm{n} / \mathrm{a}$ \\
\hline
\end{tabular}

$\mathrm{n} / \mathrm{a}=$ not applicable

the aerosol size distribution at $50 \% \mathrm{RH}$. This approach is similar to that used in field measurements. The second hygroscopicity, $\kappa_{\text {noCC }}$, includes SVOCs in the condensed phase at $50 \% \mathrm{RH}$ but neglects any further condensation as the humidity rises. This definition is used to reflect approaches that are currently used in large-scale models such as WRF-Chem to include the partitioning of SVOCs into the particle phase under subsaturated conditions. The results for $\kappa_{\mathrm{SVOC}}$ and $\kappa_{\mathrm{noCC}}$ are presented in Sect. 3.2. The third measure, called the effective hygroscopicity, carries a superscript $e$ and describes the value of the hygroscopicity of the aerosol particles without co-condensation that is required in order to produce the same number of $\mathrm{CCN}$ when co-condensation is included. This method is described in Sect. 3.3 and is applied to the aerosol both with and without the condensed phase of the SVOCs at $50 \% \mathrm{RH}$. The effective hygroscopicity could be used in models that currently do not have the capacity to simulate the formation of secondary aerosol mass or cocondensation of SVOCs. A list of the nomenclature used in the paper is summarised in Appendix A.

\subsection{Methodology}

In our model, we use the $\log _{10}$ volatility basis set of Donahue et al. (2006) with saturation concentrations, $C^{*}$, ranging from $1 \times 10^{-6}$ to $1 \times 10^{3} \mu \mathrm{g} \mathrm{m}^{-3}$. Each volatility bin represents multiple organic species with unknown material properties. In our Monte Carlo simulations we randomly select material properties of each volatility bin using a normal distribution with means and standard deviations given in Table 5 . The origins of these values are given in Table S2 in the Supplement and are based on data in the literature. To simulate uncertainty in the saturation vapour pressures of the individual compounds that are represented by the volatility distribution, we initially begin with the volatility distribution given in Cappa and Jimenez (2010), which is restated in Table 4. Some of the mass concentration in each volatility bin is then randomly redistributed between neighbouring bins to simulate uncertainties in the $C^{*}$ values of individual compounds. This process adds a random element to the relative mass concentrations in each volatility bin. The total concentration of SVOCs is then randomly chosen from a uniform distribution so that the bulk organic mass fraction of the aerosol at
$50 \% \mathrm{RH}$, without its associated water, is between 0.1 and 0.5. Further details on all of the simulated uncertainties of the SVOCs are given in Sect. S2 in the Supplement. The size distribution of the non-volatile particles was sampled using the same uncertainties specified in Sect. 2.

A Monte Carlo simulation was carried out that calculated the range of $s_{\max }$ and $N_{\mathrm{CCN}}$ that results from the parameterisation of Connolly et al. (2014) when the volatility distributions were randomly chosen from the distributions described above. In each simulation, a set of non-volatile size distribution parameters and a volatility distribution and material properties of the SVOCs were chosen randomly. Dry aerosol size distributions including condensed SVOCs were calculated at the initial RH of $50 \%$ and $D_{\mathrm{d}}$ calculated using a randomly chosen $N_{\mathrm{CCN}}$ from within its uncertainty range. The corresponding $s_{\max }$ was then used to calculate $\kappa$. A schematic of this process is shown in Fig. 1.

We first investigate the effect of uncertainty in these measurements on $\kappa$ that may result from using a CCN-based method, common in in situ measurements. In Sect. 3.3, we then go on to calculate effective $\kappa$ values that the non-volatile compounds in the absence of SVOCs would have to have in order to simulate the same cloud droplet activation affinity that the SVOCs induce. This presents a possible computationally efficient method to include the effect of SVOCs on cloud in large-scale models that currently do not have the capacity to do so directly.

\subsection{Results including the effects of SVOCs}

Using the methods detailed in Sect. 3.1, we calculated a range of hygroscopicities, $\kappa_{\mathrm{SVOC}}$, that incorporate the full effect of SVOCs on ammonium sulfate, sodium chloride, levoglucosan and sulfuric acid with $10-50 \%$ of the total aerosol mass being composed of SVOCs at $50 \% \mathrm{RH}$. The means and uncertainties of the hygroscopicity including SVOCs are plotted against the analogous quantities calculated for just the non-volatile modes, $\kappa_{\mathrm{nv}}$, from Sect. 2.2 in Fig. 3. The error bars show a marginally smaller uncertainty for $\kappa_{\mathrm{SVOC}}$, being roughly $30 \%$ of the mean, which is, at most, $10 \%$ smaller than the uncertainty associated with the non-volatile particles only. 
Table 4. Volatility distribution of SVOCs from Cappa and Jimenez (2010).

\begin{tabular}{lrrrrrrrrrr}
\hline $\log \mathcal{C}^{*}$ & -6 & -5 & -4 & -3 & -2 & -1 & 0 & 1 & 2 & 3 \\
\hline $\mathcal{C}_{j}\left(\mu \mathrm{g} \mathrm{m}^{-3}\right)$ & 0.005 & 0.01 & 0.02 & 0.03 & 0.06 & 0.08 & 0.16 & 0.3 & 0.42 & 0.8 \\
\hline
\end{tabular}

Table 5. The range of effective material parameters used for the compounds in each volatility bin. Minimum and maximum values are stated as well as the mean and standard deviation of the normal distribution from which values are sampled.

\begin{tabular}{lrrrr}
\hline Parameter & Minimum & Maximum & Mean & $\begin{array}{r}\text { Standard } \\
\text { deviation }\end{array}$ \\
\hline Molecular weight $\left(\mathrm{g} \mathrm{mol}^{-1}\right)$ & 100 & 300 & 200 & 100 \\
Density $\left(\mathrm{kg} \mathrm{m}^{-3}\right)$ & 1000 & 1500 & 1250 & 250 \\
Van 't Hoff factor & 0 & 1 & 0.5 & 0.5 \\
\hline
\end{tabular}

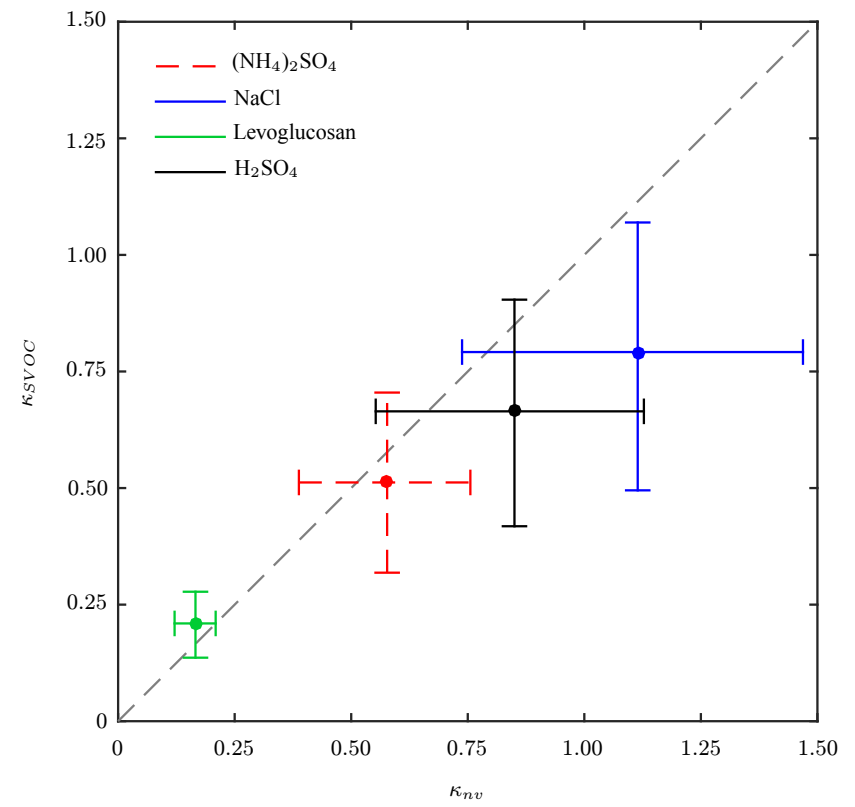

Figure 3. Hygroscopicity including the SVOCs, $\kappa_{\mathrm{SVOC}}$, plotted against $\kappa_{\mathrm{nv}}$. The grey dashed line shows equality between the axes, error bars showing the middle $67 \%$ of our derived values and the intersections of the error bars depicting the means. Ammonium sulfate is shown in red with dashed error bars, sodium chloride is shown in blue, levoglucosan is shown in green and sulfuric acid is shown in black.

The influence of SVOCs reduces the hygroscopicity of ammonium sulfate, sodium chloride and sulfuric acid. The hygroscopicity of levoglucosan is largely unchanged, with only a very slight increase, due to its chemical properties being very similar to that of the SVOCs and, consequently, the mixing rule creates little difference between $\kappa_{\mathrm{nv}}$ and $\kappa_{\mathrm{SVOC}}$. The more hygroscopic compounds, by comparison, will be more heavily affected because of a larger difference in $\kappa$ between the non-volatile aerosol and the SVOCs.

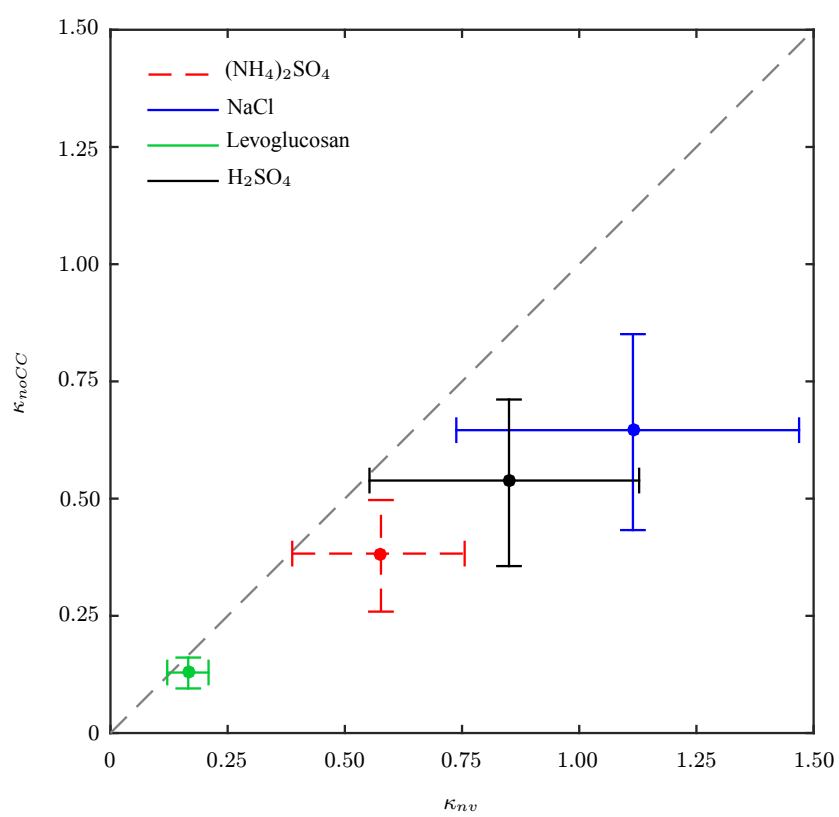

Figure 4. Hygroscopicity, $\kappa_{\text {noCC }}$, plotted against $\kappa_{\mathrm{nv}}$. The grey dashed line shows equality between the axes, error bars showing the middle $67 \%$ of our derived values and the intersections of the error bars depicting the means. Ammonium sulfate is shown in red with dashed error bars, sodium chloride is shown in blue, levoglucosan is shown in green and sulfuric acid is shown in black.

We also calculated a range of hygroscopicities that include the initial condensed mass of organic vapours at $50 \%$ RH but do not consider any co-condensation that would occur during ascent to cloud base. We denote this as $\kappa_{\text {noCC }}$ and is used to represent large-scale models that use equilibrium partitioning theory at subsaturated conditions to calculate the particle phase. The aerosol particles are assumed to be non-volatile in the parameterisation. The resulting $\kappa_{\mathrm{noCC}}$ can be calculated using the mixing rule (Eq. 4) and due to the low hygroscopicity of the SVOCs will be lower than $\kappa_{\mathrm{nv}}$. Figure 4 shows 
that the result is nearly a $30 \%$ decrease in mean hygroscopicity in ammonium sulfate, sodium chloride and sulfuric acid with a $15 \%$ reduction in levoglucosan.

Figure 5 shows $\kappa_{\text {SVOC }}$ plotted against $\kappa_{\text {noCC }}$. Both hygroscopicities are calculated using the same aerosol size distribution at $50 \% \mathrm{RH}$ and the difference is that $\kappa_{\mathrm{SVOC}}$ has further condensed mass of SVOCs added before activation. Due to the substantial decrease in hygroscopicity due to the condensed SVOCs at $50 \% \mathrm{RH}$, the mixing rule, when applied at cloud base, has a much less significant effect on the aerosol composition. The additional mass, however, will act to increase the diameter of the particles that activate in the parameterisation and this will increase $N_{\mathrm{CCN}}$ and, consequently, $\kappa_{\mathrm{SVOC}}$. The result is that $\kappa_{\mathrm{SVOC}}$ is larger than $\kappa_{\mathrm{noCC}}$ for all compounds due to the enhancement in size dominating the change in composition due to co-condensation. Figure 5 shows that the hygroscopicity of ammonium sulfate, sodium chloride and sulfuric acid increase by about $15 \%$ due to cocondensation and levoglucosan by $30 \%$.

The difference between $\kappa_{\mathrm{SVOC}}$ and $\kappa_{\mathrm{nv}}$ in Fig. 3 is the combination of both the suppression from the change in chemical composition, seen in Fig. 4, and the enhancement due to the increased size, as seen in Fig. 5. For ammonium sulfate, sodium chloride and sulfuric acid the decrease in $\kappa$ due to the change in chemical composition at $50 \% \mathrm{RH}$ dominates over the enhancement due to co-condensation and the result is a net decrease of approximately $30 \%$. For levoglucosan, the mixing rule has a less dominant effect on chemical composition than the increase in size at cloud base and, hence, the slight increase in hygroscopicity when co-condensation of SVOCs is included compared to the non-volatile compounds alone.

\subsection{Effective kappa}

In this section, we suggest a potential method to include the effects of SVOCs on cloud droplet activation in large-scale models that is computationally efficient and does include the process of co-condensation as the relative humidity exceeds $100 \%$. This approach, additionally, allows for a dependence on aerosol properties rather than assuming an arbitrary effective radius of the cloud droplets. Our method involves using our Monte Carlo simulations using the cloud droplet activation parameterisation including the effects of SVOCs (Connolly et al., 2014) to calculate the number of $\mathrm{CCN}$ for a given size distribution of non-volatile particles and volatility distribution. The effective hygroscopicity, $\kappa_{\mathrm{nv}}^{\mathrm{e}}$, is the hygroscopicity of the involatile particles in the absence of SVOCs required in order to activate the same number of cloud droplets as when co-condensation is included.

At very low updraughts, the parameterisation can be insensitive to the hygroscopicity and, consequently, there may not exist a value of $\kappa_{\mathrm{nv}}^{\mathrm{e}}$ that produces the same concentration of CCN as in the SVOC case. Similarly, at high updraughts, the parameterisation often activates all particles, even when

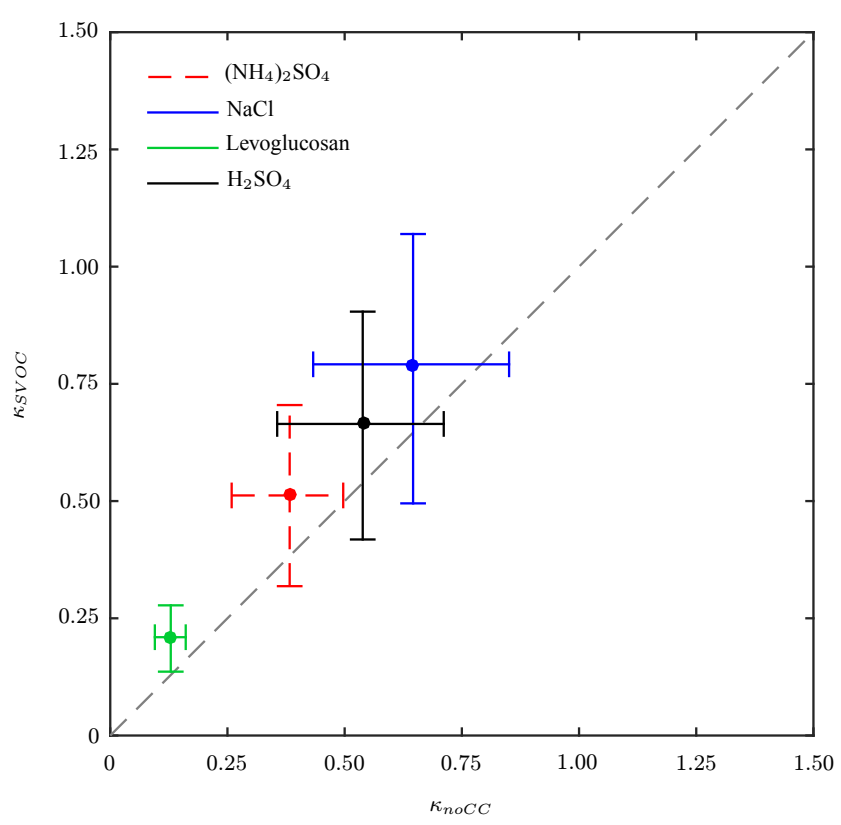

Figure 5. Hygroscopicity, $\kappa_{\text {SVOC }}$ plotted against $\kappa_{\text {noCC }}$. The grey dashed line shows equality between the axes, error bars showing the middle $67 \%$ of our derived values and the intersections of the error bars depicting the means. Ammonium sulfate is shown in red with dashed error bars, sodium chloride is shown in blue, levoglucosan is shown in green and sulfuric acid is shown in black.

the hygroscopicity is very low. To avoid these complications, we iterate the vertical updraught in the parameterisation with SVOCs until $90 \%$ of particles activate. The parameterisation without SVOCs is then evaluated at this updraught while iterating the hygroscopicity until, again, $90 \%$ of particles activate. The resulting hygroscopicity is defined as the $\kappa_{\mathrm{nv}}^{\mathrm{e}}$.

Figure 6 compares the $\kappa_{\mathrm{nv}}$ values from our Monte Carlo simulations for just the non-volatile aerosol against the effective $\kappa_{\mathrm{nv}}^{\mathrm{e}}$ values of the non-volatile aerosol. The mean effective $\kappa_{\mathrm{nv}}^{\mathrm{e}}$ values are significantly higher than the mean $\kappa_{\mathrm{nv}}$ of the non-volatile compounds in all four cases with an increase of a factor of 2 for ammonium sulfate, sodium chloride and sulfuric acid and a factor of 4 in the case of levoglucosan. The reason for this increase is that the non-volatile particles are much smaller than the particles that activate in the presence of SVOCs and, consequently, must have a larger $\kappa_{\mathrm{nv}}^{\mathrm{e}}$ in order to compensate. Neglecting the effect of SVOCs could, therefore, have a significant effect on CCN concentrations as a result of misrepresenting the aerosol hygroscopicity. The uncertainty ranges are slightly larger in the effective $\kappa_{\mathrm{nv}}^{\mathrm{e}}$ cases than the analogous $\kappa_{\mathrm{nv}}$ values but a significant increase is only observed for levoglucosan. This is due to a very small uncertainty in $\kappa_{\mathrm{nv}}$ for levoglucosan rather than a large uncertainty in the effective hygroscopicity. On average, the uncertainty spans about 30-40\% of the mean for all compounds.

Similar calculations can be carried out to study potential consequences of neglecting just the co-condensation of 


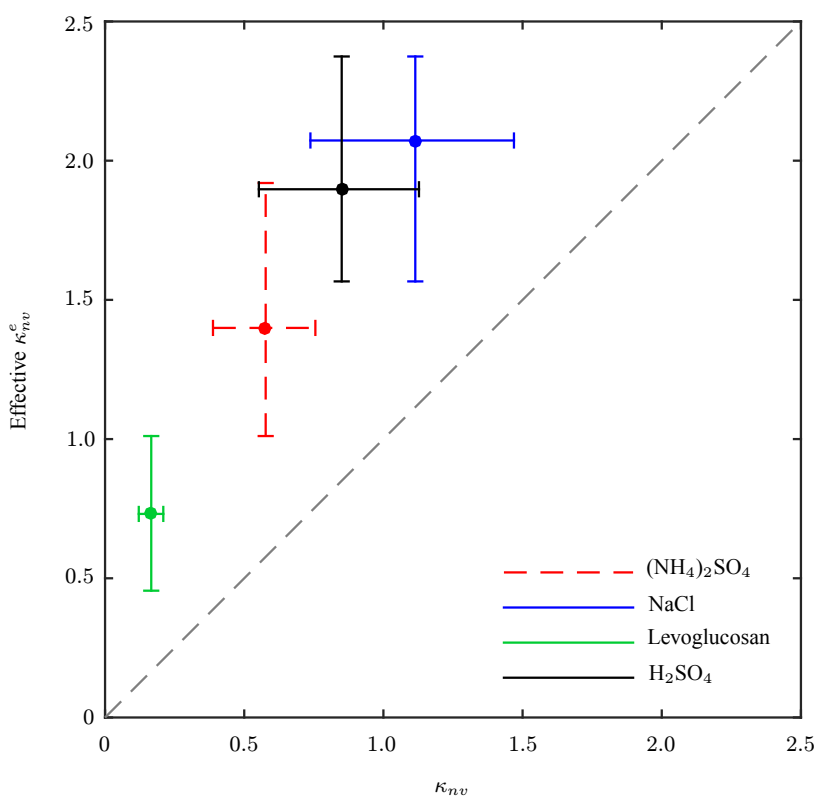

Figure 6. Effective hygroscopicity, $\kappa_{\mathrm{nv}}^{\mathrm{e}}$ plotted against the hygroscopicity of non-volatile compounds, $\kappa_{\mathrm{nv}}$. The dots show the mean values and the error bars represent the 16th and 84th quantiles. Ammonium sulfate is shown in red with dashed error bars, sodium chloride is shown in blue, levoglucosan is shown in green and sulfuric acid is shown in black. The dashed grey line shows the $1: 1$ line.

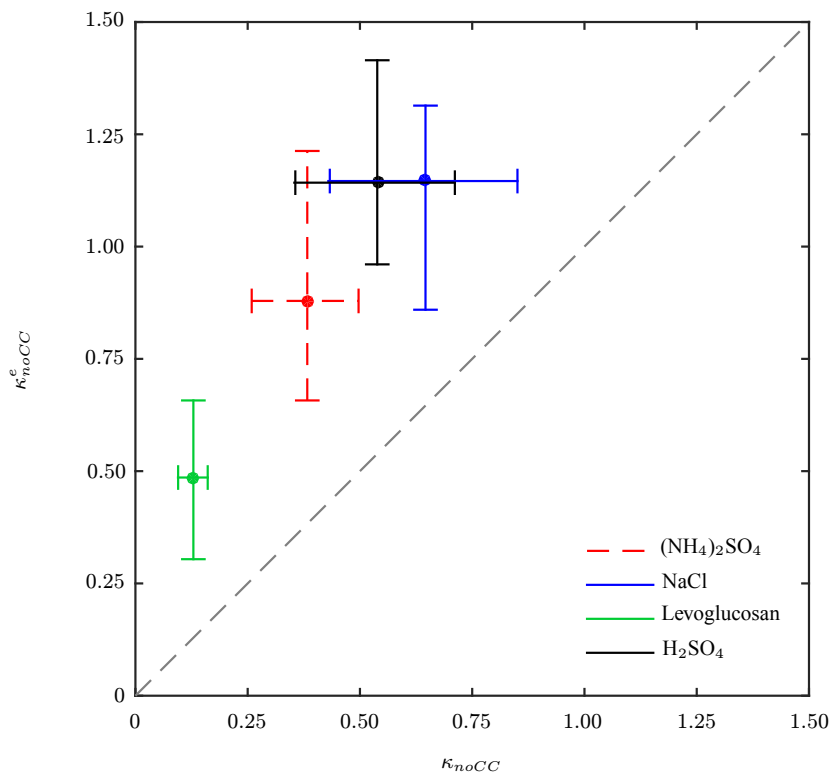

Figure 7. Effective hygroscopicity, $\kappa_{\text {noCC }}^{\mathrm{e}}$, values plotted against the hygroscopicity including the condensed SVOCs at $50 \% \mathrm{RH}$ in the absence of further co-condensation, $\kappa_{\text {noCC }}$. Error bars represent the 16th and 84th quantiles. Ammonium sulfate is shown in red with dashed error bars, sodium chloride is shown in blue, levoglucosan is shown in green and sulfuric acid is shown in black.
SVOCs in large-scale models. The effective hygroscopicity of the aerosol size distribution at $50 \% \mathrm{RH}, \kappa_{\mathrm{noCC}}^{\mathrm{e}}$, in this case can then be calculated in an analogous way to the nonvolatile case. Figure 7 compares the hygroscopicity of the internally mixed aerosol at $50 \% \mathrm{RH}$ in the absence of further co-condensation of SVOCs, $\kappa_{\text {noCC }}$, against the effective hygroscopicity of such particles, $\kappa_{\text {noCC }}^{\mathrm{e}}$. As in the involatile case, the effective $\kappa_{\text {noCC }}^{\mathrm{e}}$ values are larger than those without co-condensation, with an increase by a factor of 2 seen for ammonium sulfate, sodium chloride and sulfuric acid. Levoglucosan increases by more, as before, but only by a factor of 3. The uncertainty associated with the effective $\kappa_{\text {noCC }}^{\mathrm{e}}$ in this case is much smaller than in Fig. 6, varying by only about $0.2-0.3$, although this still represents a similar $30-40 \%$ of the mean value.

\section{Conclusions}

We propose that SVOCs have a significant impact on the hygroscopicity of atmospheric aerosol, and therefore the ability for these aerosols to form cloud droplets. The effects of SVOCs can both increase and decrease $\kappa$. The mixing rule detailed in Sect. 3.2 can shift $\kappa$ either way, dependent on the hygroscopicity of the non-volatile aerosol at $50 \% \mathrm{RH}$. If the hygroscopicity of the non-volatile aerosol is lower than the mean hygroscopicity of the SVOCs then $\kappa$ will be increased, as is the case with levoglucosan. For non-volatile aerosol with higher hygroscopicity than the SVOCs, the mixing rule will have a tendency to decrease $\kappa$ when the SVOCs are included. The magnitude of the shift in $\kappa$ is dependent upon the difference between the $\kappa$ of the SVOCs and $\kappa$ of the aerosol along with the mass of SVOCs present. Semi-volatile compounds also affect $\kappa$ by enhancing the size of swollen aerosol in the atmosphere, which consequently increases $N_{\mathrm{CCN}}$, resulting in a smaller $D_{\mathrm{d}}$ that then produces an increase in $\kappa$. These two effects contrast each other, with one being dominant over the other and which is dominant is dependant on the situation. With a full consideration of SVOCs, the overall effect is that non-volatile aerosol particles with $\kappa$ greater than that of the SVOCs give a $\kappa_{\mathrm{SVOC}}$ which is less than $\kappa_{\mathrm{nv}}$, whereas if $\kappa$ of the non-volatile aerosol is smaller than the SVOCs then $\kappa_{\text {SVOC }}>\kappa_{\mathrm{nv}}$. A larger disparity between the hygroscopicity of the aerosol and the semi-volatile compounds causes a larger translation of the mean $\kappa$.

The effects of SVOCs are also subject to the complexity of their inclusion in the model. We have shown that by omitting the effects of semi-volatile compounds during cocondensation, we obtain a lower hygroscopicity values than if co-condensation is fully included since $\kappa_{\text {noCC }}$ is less than $\kappa_{\text {SVOC }}$. It is crucial to include all the effects of SVOCs on activation, including co-condensation, because the magnitude of the underestimation of $\kappa_{\mathrm{noCC}}$ compared to $\kappa_{\mathrm{SVOC}}$ can be of similar magnitude to the overestimation of $\kappa_{\mathrm{nv}}$ compared to $\kappa_{\mathrm{SVOC}}$. 
SVOCs in the atmosphere give an effective $\kappa$ that is greater than that of the non-volatile compounds, despite the mixing rule causing a reduction in hygroscopicity for many compounds. Consequently, the co-condensation of SVOCs can significantly increase the $\mathrm{CCN}$ concentrations observed compared to those that would be expected from the involatile aerosol in environments without SVOCs. There is the necessity for them to be included into large-scale global models to avoid a drastic underestimation in the number of cloud droplets, with the potential for large global implications if not thoroughly considered.

Data availability. Fortran 90 code to perform these calculations is available from https://bitbucket.org/MattCrooks/svoc_ parameterisation. 


\section{Appendix A: Definitions of the different hygroscopicity}

\section{measures used in this paper}

\begin{tabular}{|c|c|}
\hline Symbol & Definition \\
\hline$\kappa$ & General reference to aerosol hygroscopicity \\
\hline$\kappa_{\mathrm{nv}}$ & Hygroscopicity of an involatile aerosol, as defined by Petters and Kreidenweis (2007) \\
\hline$\kappa_{\text {low }}$ & Lowest growth-factor-derived hygroscopicity stated in Petters and Kreidenweis (2007) \\
\hline$\kappa_{\text {up }}$ & Highest growth-factor-derived hygroscopicity stated in Petters and Kreidenweis (2007) \\
\hline$\kappa_{i}$ & The hygroscopicity of the $i$ th component in an internally mixed involatile aerosol \\
\hline$\kappa_{\mathrm{SVOC}}$ & Hygroscopicity that may be measured following the co-condensation of SVOCs \\
\hline$\kappa_{\mathrm{noCC}}$ & $\begin{array}{l}\text { Hygroscopicity that includes equilibrium condensed concentration of SVOCs at } 50 \% \mathrm{RH} \text { but are } \\
\text { subsequently assumed involatile }\end{array}$ \\
\hline$\kappa_{\mathrm{nv}}^{\mathrm{e}}$ & $\begin{array}{l}\text { Hygroscopicity of the involatile size distribution required to activate the same number of CCN } \\
\text { when co-condensation is included }\end{array}$ \\
\hline$\kappa_{\mathrm{noCC}}^{\mathrm{e}}$ & $\begin{array}{l}\text { Hygroscopicity of the equilibrium size distribution at } 50 \% \mathrm{RH} \text { required to activate the same } \\
\text { number of } \mathrm{CCN} \text { when co-condensation is included }\end{array}$ \\
\hline
\end{tabular}




\section{The Supplement related to this article is available online at https://doi.org/10.5194/acp-18-275-2018-supplement.}

Competing interests. The authors declare that they have no conflict of interest.

Acknowledgements. The research leading to these results has received funding from NERC, through the Research Experience Placement (REP) scheme, and the European Union's Seventh Framework Programme (FP7/2007-2013), under grant agreement no. 603445 .

Edited by: Barbara Ervens

Reviewed by: Dean Atkinson and one anonymous referee

\section{References}

Abdul-Razzak, H. and Ghan, S.: A parameterisation for the activation 2. multiple aerosol types, J. Geophys. Res., 105, 6837-6844, 2000.

Abdul-Razzak, H., Ghan, S., and Rivera-Carpio, C.: A parameterisation for the activation 1. single aerosol type, J. Geophys. Res., 103, 6123-6131, 1998.

Albrecht, B. A.: Aerosols, cloud microphysics and fractional cloudiness, Science, 245, 1227-1230, 1989.

Andreae, M. O. and Crutzen, P. J.: Atmospheric aerosols: biogeochemical sources and role in atmospheric chemistry, Science, 276, 1052-1058, 1997.

Barley, M., Topping, D. O., Jenkin, M. E., and McFiggans, G.: Sensitivities of the absorptive partitioning model of secondary organic aerosol formation to the inclusion of water, Atmos. Chem. Phys., 9, 2919-2932, https://doi.org/10.5194/acp-9-2919-2009, 2009.

Cappa, C. D. and Jimenez, J. L.: Quantitative estimates of the volatility of ambient organic aerosol, Atmos. Chem. Phys., 10, 5409-5424, https://doi.org/10.5194/acp-10-5409-2010, 2010.

Connolly, P., Topping, D. O., Malavelle, F., and McFiggans, G.: Connolly, P. J., Topping, D. O., Malavelle, F., and McFiggans, G.: A parameterisation for the activation of cloud drops including the effects of semi-volatile organics, Atmos. Chem. Phys., 14, 2289-2302, https://doi.org/10.5194/acp-14-2289-2014, 2014.

Crooks, M., Connolly, P., and McFiggans, G.: A parameterisation for the co-condensation of semi-volatile organics into multiple aerosol particle modes, Geosci. Model Dev. Discuss., https://doi.org/10.5194/gmd-2017-123, in review, 2017.

Dinar, E., Taraniuk, I., Graber, E. R., Katsman, S., Moise, T., Anttila, T., Mentel, T. F., and Rudich, Y.: Cloud Condensation Nuclei properties of model and atmospheric HULIS, Atmos. Chem. Phys., 6, 2465-2482, https://doi.org/10.5194/acp-6-24652006, 2006.

Donahue, N. M., Robinson, A. L., Stanier, C. O., and Pandis, S. N.: Coupled partitioning, dilution and chemical aging of semivolatile organics, Environ. Sci. Technol., 40, 2635-2643, 2006.
Dusek, U., Frank, G. P., Hildebrandt, L., Curtius, J., Schneider, J., Walter, S., Chand, D., Drewnick, F., Hings, S., Jung, D., Borrman, S., and Andreae, M. O.: Size matters more than chemistry for cloud-nucleating ability of aerosol particles, Science, 312, 1375-1378, 2006.

Ervens, B.: Modeling the processing of aerosol and trace gases in clouds and fogs, Chem. Rev., 115, 4157-4198, 2015.

Fountoukis, C. and Nenes, A.: Continued development of a cloud droplet formation parameterization for global climate models, J. Geophys. Res., 110, https://doi.org/10.1029/2004JD005591, 2005.

Forster, P., Ramaswamy, V., Artaxo, P., Berntsen, T., Betts, R., Fahey, D. W., Haywood, J., Lean, J., Lowe, D. C., Myhre, G., Nganga, J., Prinn, R. G., Schulz, M., Van Dorland, R., and Van Dorland, R.: Changes in Atmospheric Constituents and in Radiative Forcing Chapter 2, Cambridge University Press, 2007.

Ghan, S., Abdul-Razzak, H., Nenes, A., Ming, Y., Liu, X., Ovchinnikov, M., Shipway, B., Meskhidze, N., Xu, J., and Shi, $\mathrm{X}$.: Droplet nucleation: physically-based parameterizations and comparative evaluation, J. Adv. Model. Earth Sy., 3, M10001, 2011.

Ghan, S. J., Guzman, G., and Abdul-Razzak, H.: Competition Between Sea Salt and Sulphate Particles as Cloud Condensation Nuclei, J. Atmos. Sci., 55, 3340-3347, 1998.

Gray, H. A., Cass, G. R., Huntzicker, J. J., Heyerdahl, E. K., and Rau, J. A.: Characteristics of atmospheric organic and elemental carbon particle concentrations in Los Angeles, Environ. Sci. Technol., 20, 580-589, 1986.

Köhler, H.: The nucleus in and the growth of hygroscopic droplets, T. Faraday Soc., 32, 1152-1161, 1936.

Lance, S., Nenes, A., and Rissman, T. A.: Chemical and dynamical effects on cloud droplet number: Implications for estimates of the aerosol indirect effect, J. Geophys. Res.-Atmos., 109, D22208, https://doi.org/10.1029/2004JD004596, 2004.

Lin, G., Sillman, S., Penner, J. E., and Ito, A.: Global modeling of SOA: the use of different mechanisms for aqueous-phase formation, Atmos. Chem. Phys., 14, 5451-5475, https://doi.org/10.5194/acp-14-5451-2014, 2014.

Petters, M., Prenni, A., Kreidenweis, S., DeMott, P., Matsunaga, A., Lim, Y., and Ziemann, P.: Chemical aging and the hydrophobicto-hydrophilic conversion of carbonaceous aerosol, Geophys. Res. Lett., 33, 2006.

McCormick, R. A. and Ludwig, J. H.: Climate modification by atmospheric aerosols, Science, 156, 1358-1359, 1967.

Ming, Y., Ramaswamy, V., Donner, L., and Phillips, V.: A new parameterisation of cloud droplet activation applicable to general circulation models, J. Atmos. Sci., 63, https://doi.org/10.1175/JAS3686.1, 2005.

Morgan, W. T., Allan, J. D., Bower, K. N., Esselborn, M., Harris, B., Henzing, J. S., Highwood, E. J., Kiendler-Scharr, A., McMeeking, G. R., Mensah, A. A., Northway, M. J., Osborne, S., Williams, P. I., Krejci, R., and Coe, H.: Enhancement of the aerosol direct radiative effect by semi-volatile aerosol components: airborne measurements in North-Western Europe, Atmos. Chem. Phys., 10, 8151-8171, https://doi.org/10.5194/acp10-8151-2010, 2010.

Myriokefalitakis, S., Tsigaridis, K., Mihalopoulos, N., Sciare, J., Nenes, A., Kawamura, K., Segers, A., and Kanakidou, M.: In-cloud oxalate formation in the global troposphere: a 
3-D modeling study, Atmos. Chem. Phys., 11, 5761-5782, https://doi.org/10.5194/acp-11-5761-2011, 2011.

Nenes, A., Charlson, R. J., Facchini, M. C., Kulmala, M., Laaksonen, A., and Seinfeld, J. H.: Can chemical effects on cloud droplet number rival the first indirect effect?, Geophys. Res. Lett., 29, 1848, https://doi.org/10.1029/2002GL015295, 2002.

Ohring, G. and Clapp, P.: The Effect of Changes in Cloud Amount on the Net Radiation at the Top of the Atmosphere, J. Atmos. Sci., 37, 447-454, 1980.

Petters, M. D. and Kreidenweis, S. M.: A single parameter representation of hygroscopic growth and cloud condensation nucleus activity, Atmos. Chem. Phys., 7, 1961-1971, https://doi.org/10.5194/acp-7-1961-2007, 2007.

Pruppacher, H. R. and Klett, J. D.: Microphysics of Clouds and Precipitation, Springer, 2nd edn., 216-286, 1977.

Shipway, B. and Abel, S.: Analytical estimation of cloud droplet nucleation based on an underlying aerosol population, Atmos. Res., 96, 344-355, 2010.

Simpson, E., Connolly, P., and McFiggans, G.: An investigation into the performance of four cloud droplet activation parameterisations, Geosci. Model Dev., 7, 1535-1542, https://doi.org/10.5194/gmd-7-1535-2014, 2014.

Stevens, B. and Feingold, G.: Untangling aerosol effects on clouds and precipitation in a buffered system, Nature, 461, 607-613, 2009.

Svenningsson, B., Rissler, J., Swietlicki, E., Mircea, M., Bilde, M., Facchini, M. C., Decesari, S., Fuzzi, S., Zhou, J., Mønster, J., and Rosenørn, T.: Hygroscopic growth and critical supersaturations for mixed aerosol particles of inorganic and organic compounds of atmospheric relevance, Atmos. Chem. Phys., 6, 1937-1952, https://doi.org/10.5194/acp-6-1937-2006, 2006.

Taylor, J. W., Choularton, T. W., Blyth, A. M., Flynn, M. J., Williams, P. I., Young, G., Bower, K. N., Crosier, J., Gallagher, M. W., Dorsey, J. R., Liu, Z., and Rosenberg, P. D.: Aerosol measurements during COPE: composition, size, and sources of CCN and INPs at the interface between marine and terrestrial influences, Atmos. Chem. Phys., 16, 11687-11709, https://doi.org/10.5194/acp-16-11687-2016, 2016.

Topping, D., Connolly, P., and McFiggans, G.: Cloud droplet number enhanced by co-condensation of organic vapours, Nat. Geosci., 6, 443-446, 2013.
Topping, D. O. and McFiggans, G.: Tight coupling of particle size, number and composition in atmospheric cloud droplet activation, Atmos. Chem. Phys., 12, 3253-3260, https://doi.org/10.5194/acp-12-3253-2012, 2012.

Tsigaridis, K., Daskalakis, N., Kanakidou, M., Adams, P. J., Artaxo, P., Bahadur, R., Balkanski, Y., Bauer, S. E., Bellouin, N., Benedetti, A., Bergman, T., Berntsen, T. K., Beukes, J. P., Bian, H., Carslaw, K. S., Chin, M., Curci, G., Diehl, T., Easter, R. C., Ghan, S. J., Gong, S. L., Hodzic, A., Hoyle, C. R., Iversen, T., Jathar, S., Jimenez, J. L., Kaiser, J. W., Kirkeva?g, A., Koch, D., Kokkola, H., Lee, Y. H., Lin, G., Liu, X., Luo, G., Ma, X., Mann, G. W., Mihalopoulos, N., Morcrette, J.-J., Müller, J.-F., Myhre, G., Myriokefalitakis, S., Ng, N. L., O’Donnell, D., Penner, J. E., Pozzoli, L., Pringle, K. J., Russell, L. M., Schulz, M., Sciare, J., Seland, Ø., Shindell, D. T., Sillman, S., Skeie, R. B., Spracklen, D., Stavrakou, T., Steenrod, S. D., Takemura, T., Tiitta, P., Tilmes, S., Tost, H., van Noije, T., van Zyl, P. G., von Salzen, K., Yu, F., Wang, Z., Wang, Z., Zaveri, R. A., Zhang, H., Zhang, K., Zhang, Q., and Zhang, X.: The AeroCom evaluation and intercomparison of organic aerosol in global models, Atmos. Chem. Phys., 14, 10845-10895, https://doi.org/10.5194/acp-1410845-2014, 2014.

Twomey, S.: The nuclei of natural cloud formation part II: the supersaturation in natural clouds and the variation of cloud droplet concentration, Pure Appl. Geophys., 43, 243-249, 1959.

Twomey, S.: Pollution and the planetary albedo, Atmos. Sci., 8, 1251-1256, 1974.

Twomey, S.: The influence of pollution on the shortwave albedo of clouds, J. Atmos. Sci., 34, 1149-1152, 1977.

Zhang, Q., Jimenez, J. L., Canagaratna, M. R., Allan, J. D., Coe, H., Ulbrich, I., Alfarra, M. R., Takami, A., Middlebrook, A. M., Sun, Y. L., Dzepina, K., Dunlea, E., Docherty, K., DeCarlo, P. F., Salcedo, D., Onasch, T., Jayne, J. T., Miyoshi, T., Shimono, A., Hatakeyama, S., Takegawa, N., Kondo, Y., Schneider, J., Drewnick, F., Borrmann, S., Weimer, S., Demerjian, K., Williams, P., Bower, K., Bahreini, R., Cottrell, L., Griffin, R. J., Rautiainen, J., Sun, J. Y., Zhang, Y. M., and Worsnop, D. R.: Ubiquity and dominance of oxygenated species in organic aerosols in anthropogenically-influenced Northern Hemisphere midlatitudes, Geophys. Res. Lett., 34, L13801, https://doi.org/10.1029/2007GL029979, 2007. 